\title{
Self-Directed Learning in Teacher-Lead Minecraft Classrooms
}

\author{
Travis Faas \\ Chaolan Lin \\ Indiana University - Purdue \\ University Indianapolis \\ Indianapolis, IN 46202, USA \\ tfaas@iupui.edu \\ lin98@iu.edu
}

\begin{abstract}
Minecraft, an online multi-player sandbox video game, is now being used as a teaching tool for course subjects ranging from digital literature to computer science. To understand how Minecraft was being adopted as a classroom tool, we interviewed 16 teachers and 10 students who had used Minecraft inside a classroom setting. Analysis revealed three key ways in which Minecraft enables and motivates students to work towards their own learning goals: the ability to customize context, live through stories, and assume roles in the virtual world. Drawing from these themes we propose a set of design recommendations for online informal learning spaces.
\end{abstract}

\section{Author Keywords}

Minecraft; informal learning; collaborative learning

\section{ACM Classification Keywords}

K.3.1. Collaborative learning

\section{Introduction}

Minecraft, an online multiplayer sandbox game, provides players with an environment where they can build structures freely by connecting blocks which represent different materials, such as dirt, stone, or glass. The game gives players the ability to play in a variety of ways including building, fighting monsters, 
and making objects that help players survive or augment the world's visual appearance. Given the platform's open-ended play, teachers have been integrating it into their curricula as learning spaces that can either augment or take the place of a traditional classroom. When using Minecraft as a teaching tool, educators crafted assignments to encourage studentdriven exploration. This process can be identified as self-directed learning (SDL) which is defined broadly as a process by which individuals take the initiative to work toward a goal in understanding a subject without the assistance of others [1][8].

To understand how Minecraft was supporting SDL we conducted interviews to identify students' learning activities within and outside of their classroom's Minecraft worlds. We found that Minecraft generated and supported motivation in three ways: context creation, storytelling, and supporting student roles. These motivators often needed to be supported with additional technology, and we provide some design directions for future online informal learning systems by analyzing where both game and additional technology don't address teacher or student needs.

\section{Literature Review}

When SDL is being practiced, individuals choose and implement their own learning strategies and evaluate the outcomes [9]. Similarly, affinity spaces, where SDL often occurs, focuses on the places where people connect based on shared interests and learn from each other without an implicit teaching goal [4]. Multiplayer game settings, such as Minecraft and Second Life, can often serve as a gestation ground for affinity spaces when players get together to create art, write essays, and discuss ideas. These interactions produce informal construction of knowledge and to happen. To leverage the natural ability for Minecraft to drive SDL, many teachers have begun to adopt it into their classrooms. Teachers use the online game to teach topics such as spatial geometry, literature, digital storytelling, communication, and critical thinking [3][6].

Previous studies of SDL in classroom environments showed that students were more motivated but also worried that they may have been missing important parts of the subject matter [5]. Other work has focused on the characteristics and effectiveness of online affinity spaces that lead to SDL and how to measure the learning that was occurring in these spaces [7]. To date, little empirical work has been done to understand how Minecraft serves to motivate and support students SDL activities. In this work, we address this gap by identifying three ways the Minecraft platform supports SDL inside a classroom.

\section{Methods}

The data for this study is from a series of semistructured interviews which were conducted during November to December in 2016. Participants, composed of teachers and students, were recruited through advertisements posted to social media with further candidates identified via snowball sampling. All the students and teachers had been using Minecraft inside the classroom in 2016. The participants came from a variety of countries, majors, grade years, and levels of experience with Minecraft in a classroom context. A total of 16 teachers ( $T$ ) and 10 students (S) were interviewed. 2 from each group were female. The teachers were from the United States (12), France (2), Canada (1) and Germany (1) and taught students from grade 7 up to grade 12 . The students were from 


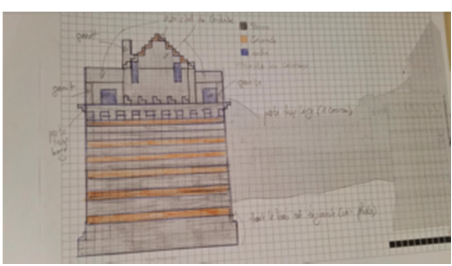

Figure 1: Student sketched the context they would like to create in Minecraft.

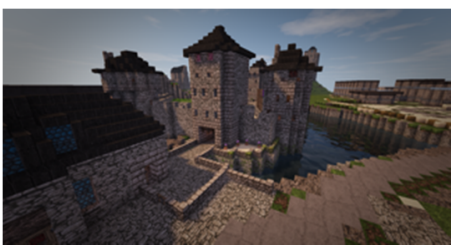

Figure 2: Student built context in Minecraft according his sketches.

NOTE the sketch and screenshot examples are included under permission of our participants and only for illustrative purposes.
Canada (4), U.S. (4), and China (2) and were enrolled in grade 3 through Freshman year of college. Subjects taught using Minecraft included social studies, game design, technology, math, computer science, history, literature, and languages such as English and Spanish.

\begin{tabular}{r|cc} 
Countries & Teachers & Students \\
\hline U.S. & 12 & 4 \\
Canada & 1 & 4 \\
France & 2 & 0 \\
Germany & 1 & 0 \\
China & 0 & 2
\end{tabular}

Table 1: Geographical distribution of participants

The semi-structured interviews were conducted via Skype or phone. Each lasted approximately thirty minutes. We focused on: 1) understanding regular teaching or learning activities that occurred both within and outside of the classroom, 2) student's continuing learning activities within the Minecraft-based classroom after the teacher's learning module is completed, and 3 ) the ways that Minecraft-based learning influenced their attitude towards learning. Additional questions examined student's collaboration and knowledge sharing practices within the game.

All interviews were audio-recorded and transcribed. The interview data then went through an open coding process with both researchers noting any themes they saw in the interviews. After open coding, the researchers put the themes into an affinity diagram [2] to identify the broad patterns both researchers agreed upon. Through our analysis, we identified three main themes that reflected the core activities and behaviors experienced by students engaged in Minecraft-based learning: (1) context creation, (2) stories, and (3) role establishment.

\section{Findings}

Adoption of Minecraft as a teaching tool typically began with the students' suggestion to use the game for a course assignment. After seeing it being used successfully by students, teachers allowed students to work on schoolwork using Minecraft as a tool for communication. A common teaching process using Minecraft involved teachers assigning open ended topics to have students explore within the game. This would push students to continue beyond the classroom instruction to use Minecraft to work towards their own earning goals, often turning to external sites like YouTube for further information.

\section{Context Creation}

The interviews with the students highlighted that Minecraft has the capability to capture student's imaginations, immerse them in a world, and give them a sense of ownership of that world. It is a game where students can change the spaces they inhabit and what those spaces mean to themselves and others. By changing the world their avatars inhabit, the students wind up changing the context of their play. What was originally an open field might become an alien landscape or a Mayan temple. Describing how he experienced the game, S2 said, "It felt like a combination between this open world game, and something we created. It was this massive world from all these students." Teachers explicitly tried to provoke these feelings of wonder and ownership by allowing students to manipulate their Minecraft worlds. "I like to 
have them become creators of content" was a statement by $\mathrm{T} 2$ that was echoed by others.

The manipulation of context could convey meaning both in an establishment of setting, but also in more concrete ways. In one example T10 assigned students to use Minecraft to communicate the concept of positive and negative numbers in game. The students created a variety of spaces such as holes, towers, and farms to express the concepts of positive and negative numbers in a way that could be experienced by their peers. The course teacher (T10) was surprised by their student's tendency to learn outside of the classroom to create unique expressions of the range of numbers.

Students also took the lead to develop spatial contexts to support peer interaction in the game. These spaces enabled the development of social, civic, economic, geographic, and architectural knowledge. The drive to create space for oneself and one's community was so strong that one-third $(n=5)$ of the teachers noted that students would build their own house for themselves and form virtual communities, often without prompting. T3 noted that these societies formed based around a need to collaborate to fulfill in game needs for ore, pelts, and farmed goods. In many cases an economy based on bartering developed and was later supported by the instructor with an in-game "currency" stand in, such as emeralds.

The ability to manipulate spatial context and meaning of those spaces in Minecraft is a motivator for students. They can create spaces that are personally meaningful for them and their peers. While they are constructing these spaces, they are often lead to questions about what they want to build for their shared world that they seek to answer via external resources.

\section{Storytelling}

Storytelling was a common way to motivate students engagement with the course material in Minecraft. Teachers used non-player characters (NPCs) and gameplay rules to tell stories in the spaces the students had created. These NPCs were part of a set of changes to the functionality of Minecraft (or mods) that the teachers installed that added features the game did not have originally. These mods enabled "questing systems" found in other role playing games (RPGs), such as World of Warcraft, a massively multiplayer online role-playing game. Students were often tasked with building upon a minimalistic story with their own NPCs and stories. When the students built the stories it was common to see them using external resources to learn how to further mod the game to create quests and manipulate the game code by themselves. In other cases, the instructors had the NPCs set up to reward in game actions with currency or other valuables.

When speaking about their use of stories, T12 said, "This engages them on a whole new level. They are ... physically living it." An example of the use of NPCs and stories employed by a teacher to motivate students is provided by $\mathrm{T} 7$ who used both to create an immersive world with thriving historical villages that required students to interact in Spanish. S6, a student of T7, noted that it was his engagement in this world that helped him stay immersed in the language for his two years in the Spanish class. T7 reinforced this sentiment and added, "[Minecraft] seems so silly that they're not themselves. It's a nice way to be able to roleplay with them." 
Roles

Unlike many other classroom technologies, Minecraft has a double identity as a constructive learning space and as a game. The inclusion of game elements resulted in a set of player types emerging with students filling roles of hunters, socializers, miners, and crafters/builders. While these specializations formed naturally, the teachers later reinforced them either by explicit roleplay rules built into the game (which required students to only do one job in the game) or by quests that rewarded play centered on specific roles. Both reinforcement strategies were used to cement the societies that had been created by the spaces and stories. In referring to his use of Minecraft to teach history, T2 stated, "I let them experience this life as a peasant, but they then get to follow and figure out what they want to be."

The roles that students adopted affected the progress of their self-directed learning. To succeed in these roles, students used external resources such as Minecraft forums to continue learning and to interact with others interested in similar topics. One student who adopted a "builder" role would record their work in Minecraft and showcase their work via screenshots or video recordings on YouTube. S7, a high school student, said that "if you say what is the matter that inspired me to learn programming (in Minecraft), the urge to create something cool in Minecraft and show off to friends would be it."

\section{Discussion}

Minecraft, which was originally built as a survival and crafting game, has been appropriated by both teachers and students to keep engagement high and to communicate ideas with one another. The ability for students to modify contexts - to change the spaces, the stories, and the lives they are living within them motivates them to engage with materials both inside and outside of the courses. As these students continue to build and play within the worlds they are making they would naturally find resources to help them acquire the skills they needed in game. In the case of a classroom incarnation of Minecraft, the teacher is responsible for establishing initial contexts and guiding students in a direction that they hope will bring about desired learning objectives. For teachers and students, the current incarnation of the game is lacking in several areas including teaching planning tools, metrics gathering for role tracking, and context scaffolding.

Collaborative construction of space is common in Minecraft, and with collaboration comes the need to plan who will be building what. Teachers have an additional need to plan what the students are building and link those plans to learning outcomes. Technology needs to be developed that can support planning the milestones they want their students to achieve during their construction of the contexts and stories.

Milestones might include specific story points, roles to be filled, and locations to be built. Metrics gathered on student build time and progress could help an educator design their future use of Minecraft to ensure they can hit all their required learning objectives in a course.

A metrics system would need to consider the roles that students play in the world. This system should be able to show both progress towards course milestones, and how the play styles adopted by the students are contributing to that progress. Because the process of creating context often revolved around the use of virtual economies, one avenue to tracking behaviors 
and rewards - and encouraging students to take preferable roles - is to monitor the inputs and outputs of the economics system in the game. Currently these systems are often done ad hoc or manually by a teacher. If the economies were automated, quick reports could be generated for a teacher at the end of a day. These transactions would be one way to determine the playstyle makeup of a class and what directions might work best for getting the students engaged with the course content.

The process of building NPCs, writing stories, and creating physical contexts takes a significant investment of student time which can be detrimental to a class where construction is only incidental to the goals of the course. Some approaches to using Minecraft in a class attempt to overcome this by using previously built worlds and stories. This approach destroys some of the motivating qualities of Minecraft, including the ability to customize one's home and have control over the context of the world. Finding a balance between building the world and acting within the world needs to be found. Potential solutions include either a set of prebuilt thematic assets that can be placed in world via a user interface accessible to the students or worlds that have been planned to support small areas of building that can be completed in less time.

\section{Limitations and Future Directions}

Several limitations exist in this study. While the study does have a focus on student experience, many of the stories associated with the students were gathered from teachers. These stories may have been influenced by the teacher's interests and preoccupations. In addition, both the teachers and the students were quite enthusiastic about their use of Minecraft throughout their class time. Though both teachers and students expected to move on from Minecraft as the students aged, the excitement about the game may have lead to biased interviews - our sampling method was not able to uncover those who tried Minecraft and had given up on it early.

Future work might include observations of students to understand how roles are negotiated when the Minecraft societies are first created, and if these roles adequately represent the playing preferences of the students. Further field studies could be targeted towards gaining a deeper understanding of how students decide what to build and where. Knowing how students assume roles and make spaces could then be used to inform a model that could be used to build a mod that adds in student tracking tools mentioned in the discussion.

\section{Acknowledgements}

The authors would like to thank all the teachers and students who either gave us the time for these interviews or put us in contact with others who would like to speak with us and Dr. Lynn Dombrowski along with Dr. Alyson Young for their review and advice.

\section{References}

1. Jonas Boustedt, Anna Eckerdal, Robert McCartney Kate Sanders, Lynda Thomas, and Carol Zander. 2011. Students' perceptions of the differences between formal and informal learning. In Proceedings of the seventh international workshop on Computing education research (ICER '11). ACM New York, NY, USA, 61-68. DOI:

http://dx.doi.org/10.1145/2016911.2016926 
2. Hugh Beyer and Karen Holtzblatt. 1999. Contextual design. interactions 6, 1 (January 1999), 32-42. DOI=http://dx.doi.org/10.1145/291224.291229

3. Stephen Brookfield. 1985. Self-directed learning: A critical review of research. New Directions for adult and continuing education, 1985(25), 5-16.

4. Rosemary S. Caffarella, Judith M. O'Donnell. 1989. Self-directed learning. Department of Adult Education, University of Nottingham, Nottingham.

5. Sean C. Duncan. Gamers as Designers: a framework for investigating design in gaming affinity spaces. E-Learning and Digital Media, 7(1). 21-34.

6. James Paul Gee. Situated language and learning: $A$ critique of traditional schooling. Routledgem, New York, 2004.
7. Malcolm Shepherd Knowles. 1975. Self-directed learning: A guide for learners and teachers.

Association Press, New York.

8. Steve Nebel, Sascha Schneider and Günter Daniel Rey. 2016. Mining learning and crafting scientific experiments: a literature review on the use of minecraft in education and research. Journal of Educational Technology \& Society, 19(2), 355-366.

9. Mark Walton. 2012. Minecraft in education: how video games are teaching kids. GameSpot. CBS Interactive. Retrieved February 22, 2015 from http://www.gamespot.com/articles/minecraft-ineducation-how-video-games-are-teachingkids/1100-6400549/ 